\title{
Learner Characteristics' Factors and their Relationship with Drop-Out in Distance Learning: The Case of the Arab Open University in Saudi Arabia Riyadh Branch
}

\author{
Manal Ahmed Ibrahim ${ }^{1,2}$, Beatrice I. J. M. Van der Heijden ${ }^{3,4,5,6,7}$ \\ ${ }^{1} \mathrm{HRH}$ Prince Talal Al Saud Institutions, Riyadh, Saudi Arabia \\ ${ }^{2}$ DBA Graduate Maastricht School of Management, Maastricht, The Netherlands \\ ${ }^{3}$ Radboud University, Institute for Management Research, Nijmegen, The Netherlands \\ ${ }^{4}$ Open University of the Netherlands, Heerlen, The Netherlands \\ ${ }^{5}$ Kingston University, London, UK \\ ${ }^{6}$ Hubei University, Wuhan, China \\ ${ }^{7}$ Ghent University, Ghent, Belgium \\ Email: manal.ahmedyousef@gmail.com, b.vanderheijden@fm.ru.nl
}

How to cite this paper: Ibrahim, M. A., \& Van der Heijden, B. I. J. M. (2019). Learner Characteristics' Factors and their Relationship with Drop-Out in Distance Learning: The Case of the Arab Open University in Saudi Arabia Riyadh Branch. Psychology, 10, 199-212.

https://doi.org/10.4236/psych.2019.102016

Received: November 1, 2018

Accepted: January 29, 2019

Published: February 2, 2019

Copyright $\odot 2019$ by author(s) and Scientific Research Publishing Inc. This work is licensed under the Creative Commons Attribution International License (CC BY 4.0).

http://creativecommons.org/licenses/by/4.0/

\begin{abstract}
In this study, learner characteristics' factors were examined to predict student withdrawal from, or completion of, university distance education programs. The research model was examined using face-to-face in-depth interviews followed by a pilot sample of 127 students, and then re-examined among a sample of 587 students. A quantitative approach was the dominant technique using factor analysis, followed by discriminant analysis aimed at testing the predictive validity of the distinguished factors in the light of withdrawal or completion. The outcomes of our empirical study indicate that having an independent learning style is the factor that significantly discriminates between students who leave and those who remain at the Arab Open University (AOU) in Saudi Arabia.
\end{abstract}

Keywords

Learner Characteristics' Factors, Distance Education

\section{Introduction}

Distance learning (DL) is not a new trend in the field of education. In fact, distance learning can be traced back to the late 1800's when correspondence 
courses were first introduced (Willis, 1994). DL comprises teaching of students who not always are physically present in an educational institution. In the Arab region, there are three modes of distance learning institutions: dual mode, single mode, and virtual mode. A dual mode university is an institution that provides conventional and distance education simultaneously. A single mode university is an institution wherein distance education is the sole mission to which teachers and administrative staff are exclusively dedicated. More specifically, course development, instruction, evaluation and other educational processes are tailored to meet the needs of the distant learner. As regards the third mode, that is the virtual mode, an institution that conducts this mode of distance learning providing a world-class education without limitations and aimed at making strong connections between the Arab region and the western world. The objective of such a university is to bring American, European, and other international universities to each home base in the Arab States so that students do not have to leave their countries to study abroad. Besides, the degrees awarded are internationally accredited (Mohamed, 2005).

DL is further enhanced and stimulated by the interest created among educators and technologists, all over the world, to experiment with various forms of distance and flexible learning. Consequently, DL has now emerged as one of the preferred options for millions of individuals who wish to study and learn at their own place, in an atmosphere that is compatible with their own needs and interests (Paustain \& Slovenes, 2002; Ried, 2010; Traxler, 2018). Recent empirical work indicated that in American universities more than one third of all students have taken at least one on-line course throughout their study (Bonk \& Khoo, 2014).

Nowadays, we have seen a vast and rapid growth of DL practices at all levels of education, and DL fulfils an integral role in overall educational and training provision (Simpson, 2012; UNESCO, 2002). Besides, the National Centre for Education Statistics (NCES) in the USA claimed that the overall number of DL programs has risen up tremendously. For instance, at the University of Florida, DL was thought to meet the demand of students and to accomplish the educational institution's strategic plan, focussing on improving cultural diversity by facilitating access to students without binding them with geographical limitations (Ried, 2010).

Accordingly, both government and private sectors will have to renew and renovate themselves in order to meet students' demands, while those institutions that cannot cope with the new situation (in terms of upgrading their competitive edge) will be deliberately excluded from the marketplace (Kamel, 2002). Also, DL, with its flexibility and accessibility, plays a vital role in some countries, where the traditional system of education has shown to be insufficient in terms of covering the education and learning needs of the immediate community, particularly in the rural areas and densely populated regions (Gandhe, 1995; Zambalde et al., 2012). Moreover, DL can be of great benefit to adults who have missed their chances for traditional education earlier in life. It can also be a very 
fruitful approach for employees who do not have sufficient time available to attend a regular training program. On top of all clients come the women who are not able to enrol for study on male campuses due to cultural considerations (think, for instance about the Arab world), and who receive much of their instruction by DL means of remote communication (Rawaf \& Simmons, 1992).

Although it is clear that DL widens the scope of educational opportunities for those learners who already have an access to educational facilities, the high attrition in DL institutions is regarded as a dilemma, for which no appropriate solution has been found yet. All over the world, empirical research has indicated that the attrition rate of DL students is significantly higher than that in traditional classes (Carr, 2000; Diaz, 2002; Frankola, 2001; Rwegasira, 1988; Simpson, 2012). The percentage of students who drop out of traditional education remains constant, i.e., between $40 \%$ and $45 \%$ (Tinto, 1982), while in DL the drop-out rate appears to be $10 \%$ to $20 \%$ higher in comparison with traditional education (Carr, 2000; Diaz, 2002; Frankola, 2001; Simpson, 2008). In a recent study, it was found that $40 \%$ of academic leaders in higher education in the USA felt that it was harder to retain on-line learning students than face-to-face students (Bonk \& Khoo 2014).

In this contribution, we will go into the problem of student retention and attrition in the Arab world by means of research on DL in Saudi Arabia, in specific at the Arab Open University (AOU), 2018. AOU is an example of a single mode university that uses hybrid courses comprising the advantage of both face-to-face and online learning for their learners. AOU was established under the umbrella of the Arab Gulf Program for United Nations Development Organizations (AGFUND), adopting broad regional educational goals. Its main campus is in Kuwait, and it extends to cover different Arab countries: Bahrain, Egypt, Lebanon, Jordan, Oman, Sudan, Palestine and Saudi Arabia. In Saudi Arabia, it has six different branches, which are located in Riyadh, Jeddah, Ha'il, Al Madinah, Al Dammam and Ehssa'. The model as adopted by AOU resembles that of the United Kingdom Open University, especially in areas of materials and consultancies, with a few adaptations in pre-entry qualifications. More specifically, AOU requires pre-entry qualifications that confine accessibility to those who aim to get academic credits.

According to the records of AOU, there are a lot of students who fail to persist with degree completion, and herewith fulfilment of their goals. However, the reasons why these students drop out of university are not well understood, and require more attention in sound empirical research (Gibson, 2000), with the Arab world being no exception (Mohammed, 2005). Moreover, a great bulk of literature on the effects of on-line education, that has recently been written, has focused upon learners' outcomes and course evaluations (Russell, 1999), yet has largely neglected the role of learners' characteristics.

Predicting student outcomes is actually a process of trying to determine what category an individual student belongs to. That is to say, we aim to distinguish 
between students under the category of attrition and students under the category of retention. Attrition refers to the decrease in the number of students enrolled in some courses; and such decrease can be attributed to one reason or another. An antonym of attrition is retention. Retention refers to those students who are promoted from one phase of education to the next, and who stay enrolled over (a considerable period) of time. For the purposes of developing a model of attrition and retention of students in DL, a drop-out is considered any student who enrolled at an educational institution for one semester, but who does not enrol for the next semester. Unlike attrition, retention will refer to any student who enrolled at an educational institution one semester, and continues to enrol into the next one.

The main objective of this paper is to examine to what extent learner characteristics' factors affect attrition or retention of students in DL. More specifically, the attrition or retention rate is determined through the identification of these characteristics that differentiate significantly, from a statistical point of view, between DL students who leave and the ones who remain.

\section{DL in the Arab World: Practice and Challenges}

The Arab world has witnessed a notable increase in enrolment rates in higher education institutions. This increase is due to a number of reasons amongst which is the constant increase in public demand for education, being a direct and natural result of high rates of population growth (Mashhour, 2007). Nevertheless, most Arab governments are not financially capable of meeting these increasing demands. In this context, DL with its modern communication facilities and technologies has appeared as a promising approach in an attempt to solve the dilemma. According to a report published by UNESCO in 1998, DL succeeded in making available the chance of pursuing higher education at a reasonable cost.

In the Arab world, there are three modes of DL institutions: First, the dual mode university, which comprises an institution that provides conventional and distance education simultaneously. There are several established examples, such as the Open Learning Centre in Egypt, and the Distance Education Centre of Juba University in Sudan and Jordan. Second, the single mode university, wherein distance education is the sole mission to which teachers and administrative staff are exclusively dedicated. This category encompasses many examples in some Arab countries, such as the Open University in Libya, Al-Quads Open University in Palestine, and the Arab Open University, 2018 in Saudi Arabia. Finally, there is the virtual mode, such as the Syrian Virtual University, which is the first on-line university in the Arab world. It was established in 2002 to provide world-class education without limitations, and aimed to link the Arab world to the West (Mohammed, 2005).

Culturally speaking, Arab countries have many features in common, particularly on linguistic and religious levels. However, there are obvious differences 
amongst them in many aspects as well, such as population size, national income, natural resources, stability, and prosperity.

The Arab League Educational, Cultural, and Scientific Organization (ALECSO) has identified a number of factors that may have a negative impact on the growth of distance education in the Arab world. First, traditional instructional media, such as printed materials, are still used broadly at open education institutions. Second, the main bulk of part-time instructors is hired on a loan basis from the traditional universities, and is not trained to conduct classes of distance higher education. As such, their attitudes towards distance education are not much different from those adopted by many people who look at distance education as a second-class form of education. Third, the majority of the Arab societies are still sceptic about the practices of DL education programs, believing that $\mathrm{DL}$ is another form of correspondence instead of a novel approach to instruction. This blurred image is even enhanced by the fact that quite a few DL students fail to finish their program. Fourth, some Arab countries do not recognize distance education institutions, and therefore do not confer a degree upon their graduates. Altogether, these factors have serious implications for the further development of DL approaches in the Arab region.

To redress the doubts surrounding the concept and the practice of distance education, considerable efforts should be made to ensure low attrition rates on such programs. In other words, the retention of distance higher education students in the Arab world must be taken seriously if Arab countries want this mode of education to thrive. Developing a strategy to decrease the drop-out rates for distance learners would be helpful in guiding those in charge of implementing such models in the region, and it would be a major step towards attaining accreditation of such institutions and their programs by internationally recognized bodies. In the next section, we will go into a review of literature on student attrition and retention aimed at determining the variables of interest that ought to be taken into account in empirical research in the field.

\section{Review of Literature on Student Attrition and Retention}

From a historical perspective, the percentage of students who drop out of traditional higher education remains constant between $40 \%$ and $45 \%$ (Tinto, 1982). In the context of on-line learning, drop-out rates appear to be higher than those rates in traditional learning are. Despite the unavailability of reliable national statistics for completion rates of DL students, drop-out rates are believed to be $10 \%$ to $20 \%$ higher, according to researchers in this field of study (Carr, 2000; Diaz, 2002; Frankola, 2001; Simpson, 2008). This outcome needs to be taken seriously since student attrition is usually implying extra money, effort and time for all parties involved. In order to further demonstrate this, the work by Tillman (2002) may be helpful. Tillman (2002), in a study at Mountain Empire Community College, found that the drop-out rate mounted to about $50 \%$ of first-to-second-year. More specifically, the whole Mountain Empire Community 
College population collaborated in reviewing its records, and it was found that there was a deterioration of more than five million dollars in tuition revenue. The latter appeared to be due to student attrition over the three years preceding the study. Obviously, with an annual operating budget of less than 10 million dollars, this amount was deemed to be significant.

When reviewing the previous literature, it has been found that the phenomenon of attrition and retention incorporates a lot of controversy and complexity, and comprises a variety of dimensions. In general, the retention theory basically discusses the factors that influence student retention positively or negatively (Kinder et al., 2002). Several theoretical models of retention have been offered in both domains of traditional learning and DL (Bean \& Metzner, 1985; Boshier, 1973; Boyles, 2000; Braxton et al., 1997; Frankola, 2001; Garland, 1993; Kember, 1981; Khan et al., 2018; Kinder et al., 2002; McEwen \& Gueldenzoph, 2003; Morris \& Finnegan, 2005; Puspitasri \& Oetoyo, 2018; Tinto, 1975, 1982, 1993; Sweet, 1986; Tillman, 2002; Traxler, 2018).

Tinto's theory, developed in 1975, and elaborated on in 1982 and 1993, respectively, is one of the most widely recognized retention theories in this field of study. Cabrera, Castaneda, Nora, and Hengstler (1992) pointed out that individual attrition from academic institutions can be ascribed to a longitudinal process of interactions between an individual and other members of the academic and social systems of the institution, herewith stressing the importance of individual factors and institutional involvement in attrition and retention research. Bean and Metzner (1985), on the other hand, considered attrition behaviour as a function of the person and his/her environment, and, given the fact that DL students do not regularly attend classes on campus, emphasized the need to take external environment factors into account, rather than so-called social integration variables that mainly affect traditional students on campus (Boyles, 2000).

As regards the individual factors, being the focus of our study, students who enjoy an independent learning style and who are less influenced by their environment are more suitable for DL courses (Diaz \& Cartnal, 1999; Heidrich et al., 2018). As such, increased awareness about student learning preferences can assist the instructor in class preparation, designing class delivery methods, choosing appropriate technologies, and developing sensitivity in accordance to different student learning preferences within the DL environment. This will help to create a successful process of education, and, hence, probably result into more retention of students (Diaz \& Cartnal, 1999). Moreover, Parker (1999) and Morris \& Finnegan (2005) found that locus of control was highly significantly correlated with student drop-out from DL. Learners with an internal locus of control tend to have higher rates of completion in DL (Dille \& Mezack, 1991; Morris \& Finnegan, 2005; Parker, 1999), because they are more inclined to invest the necessary time and hard work, and expect this effort to positively affect their academic achievement (Dille \& Mezack, 1991; Thompson, 1998). 
Another factor of importance comprises students' belief in the advantage and value of DL. Recent developments in information technology assist DL in becoming more flexible and in breaking the barrier of time and location (O'Malley \& McCraw, 1999). However, on-line students often require more time to be adjusted to the virtual course than the time invested in a face-to-face session. DL delivery methods are considered to be an innovative or rather a novel approach in educational systems (Yang \& Cornelius, 2005) that needs to be carefully implemented in order to be evaluated positively (Nasser \& Abouchedid, 2000).

As regards some other individual factors, we stress the importance to incorporate prior educational skills, such as, reading and writing. In a typical DL class, nearly all communication is achieved through writing, so it is necessary that students feel comfortable in expressing themselves in writing. Meaningful and high-quality input into the on-line classroom is an essential part of the learning process in DL. In the next section, we will go into the methodology of our empirical scholarly work.

\section{Methodology}

\subsection{Sample and Procedure}

The random sampling technique was used in order to sample students who are enrolled in AOU $(\mathrm{N}=4000)$. In order to increase the motivation of possible participants to our study, the AOU University Administration permitted the researcher to assign three gifts as an incentive, and a bonus to be given to those who would complete their task with enthusiasm and accuracy. Using a $95 \%$ confidence level is the most common rule used for calculating the optimal random sample size. By convention, a sample error of 5\% was accepted, thus allowing a sample of 400 students. This sample was used for estimation and development of the discriminant function (retention versus attrition), while the additional 187 respondents were used for cross-validation of the discriminant analysis results, being the hold-out sample.

\subsection{Measures}

The questions of the survey were designed using a five-point Likert scale (please see Table 1 for an overview of all items). The researchers then re-categorised the answers of the dependent variable to combine the "totally disagree" and "extremely disagree" into one category, to combine the "totally agree" and "extremely agree" into another category, and to disregard the undecided. Moreover, the students surveyed were given the opportunity to write down some open-ended comments. Those students who continued their study at the AOU were classified under "retention", and those who did not continue their study were considered drop-outs, and therefore classified under "attrition". To minimize the measurement error, internal validity and face validity were investigated, and appeared to be good. Cronbach's Alpha $(\alpha)$ test was applied to investigate the internal 
Table 1. Rotated Component Matrix of Factor Analysis (factor loadings).

Factor 1. Independent learning style

18 -I prefer to work by myself on assignments in my courses.

22-I learn a lot of the content in my classes on my own.

23-I feel very confident about my ability to learn on my own.

27-I prefer to work on class projects and assignments by myself.

28-When I do not understand something, I first try to figure it out for myself.

0.601

Factor 2. External locus of control

13-If I study hard enough, I can succeed any exam.

14-A person is responsible for her/his own actions, good or bad.

16-A person can change his/her personality and behaviour patterns.

0.603

Factor 3. Believe in the advantage and value of DL

02-I prefer the AOU because I have not enough time to spend in the regular university classes.

4-Flexibility is the main advantage of the study in AOU.

29-I really believe in the value of distance learning.

Factor 4. Doubt in the advantage and value of DL

30-I feel confident using the computer.

$34-$ I do not appreciate the value of distance learning.

$36-I$ believe I am a good user of the computer.

70-I intend to leave the AOU.

Factor 5. sharing skills

24-I like to develop my own ideas about course content.

25-I have my own ideas about how classes should be run.

\section{Factor 6. Writing skills}

33-I find difficulty in expressing myself in writing.

$41-$ It is easy for me to communicate through writing.

\section{Factor 7. Internal Locus of control}

6-Heredity determines most of a person's personality.

08-Intelligence is a given and cannot be trained.

$11-$ Bad or good luck can really follow you around.

Factor 8. Reading skills

$31-$ I enjoy reading books and magazines.

$35-$ In general, I do not like reading.

\section{Factor 9. Self-confidence}

10 -If you set realistic goals, you can succeed no matter what.

20-My ideas about the content often are as good as those in the textbook.

\section{Factor 10. Socio-economic effect}

09-School success is mostly a result of one's socio-economic background.

Factor 11. Cost effect

05-I prefer AOU because of its low fees.

\section{Factor 12. Last resort}

03-The AOU is the only access to finish my university study.

Factor 13. Believe in chance

$07-$ Chance has nothing to do with being successful. 
consistency of the students' responses. The reliability was appropriate, i.e., .6511, implying that further analyses could be conducted (Hair et al., 1998).

Moreover, semi-structured in-depth interviews were conducted with the teaching staff, administrators, students, and the students' parents in the AOU. The interviews started by asking the respondents a series of general questions, and they were encouraged to talk freely about their attitudes towards distance learning. Initial questions were asked using a semi-structured format. Since probing is important in obtaining significant insights, the researcher used laddering and funnelling techniques to extract the hidden issues. Next, a content analysis was conducted. The measuring unit of this content analysis comprised the appearance of distance learning values and the recognition of those factors that led to attrition.

\subsection{Analyses Strategy}

First, checks for missing values, outliers, multivariate normality and linearity were performed and all necessary assumptions appeared to have been met. Next, the major assumption for discriminant analysis, being a non-metric and categorical dependent variable (with two groups), was tested for as well. The independent variables appeared to be metric, normally distributed, but equal in dispersion and covariance structures (matrices). Next, factor-analytic approaches were used to determine the factor structure of the variables and to test the validity of the measures. Discriminant analysis was applied to determine which variables best discriminate between the so-called attrition and retention clusters of students. It is the most appropriate technique in this regard because the dependent variable consists of two mutually exclusive and collective categories: attrition or retention, and the predicting variables are metrical (Hair et al., 1998; Malhotra, 1999; Astin, 1970).

Next, step-wise estimation minimizing Wilks' Lambda was used to determine the discriminant function. That is to say, all factors were entered into the discriminant analysis using a step-wise technique, which allows for the determination of variables' relative discriminant ability. Furthermore, the variable that maximizes the Mahalanobis distance between the two closest groups will be entered. In this analysis, the overall impact of the discriminant function is observed using a .05 significance interval.

\section{Results}

First, exploratory factor analysis was conducted, given the fact that this was the first empirical study in this field in the Arab context, and in order to eliminate badly differentiating items. The used cut-off point for the Eigenvalues was 1, and items with factor scores below 0.5 were eliminated from further analyses. See Table 1 for the outcomes of our exploratory factor analysis.

Next, discriminant analysis was applied to the variables with factor loadings $>$ 0.5 resulting from the above-mentioned factor-analytic approach. The standard- 
ized discriminant function coefficients serve the same purpose as beta weights in multiple regression analysis. That is, they indicate the relative importance of the independent variables in predicting the dependent. The final discriminant function, which resulted from our analysis, can be formulated as follows:

Actual dropout $=1.0004$ Independent Learning style +0.001

In conclusion, the results of our empirical work seem to point out that an independent learning style is the key factor in keeping the students in the DL system at the AOU in Saudi Arabia. An important follow-up question was: How well does this formula (model) perform in a predictive categorization or classification? Therefore, we used this discriminant function to test its so-called discriminative power, using the additional sample of 187 respondents (the previously explained hold-out sample). The use of the additional sample data helped us in avoiding "over-fitting" the model. In particular, over-fitting could have happened in case that the discriminative power was tested using the data that was used to develop the formula. This is why we chose for new data for our cross-validation purposes. The overall hit ratio turned out to be $61.6 \%$ (correctly classified cases of retention versus attrition). This performance is better than what could have been achieved by mere chance.

\section{Discussion}

Retention at educational institutions plays a vital role in policy development. For this reason, decision-makers working in higher educational institutions across the world have to choose models that will optimally suit their student selection and retention. AOU is the first university to use distance learning education systems in Saudi Arabia, where the rest of the educational institutions are using traditional forms of education. All in all, the outcomes of our study support the view that personal characteristics of learners play a fundamental role in higher education, in particular, indicating the importance of an independent learning style from students. Concrete, our research demonstrates that students with independent learning style orientations are more likely to succeed in distance learning. This implies that the programme administration in distance education institutions needs to refine tests in the university admission policy and procedures that can best identify this personal attribute in the applicants.

Future empirical work is needed to better understand how the design of distance learning education programs should be adapted, and to know how to cherish this learning style and to make the most out of it. In addition, more scholarly research is needed to investigate the generalizability of the outcomes across countries. Finally, more research is called for to take into account the possible effect of other variables, such as, bureaucracy in the educational institution, mission and policy, budgeting and funding, and institutional factors in countries.

\section{Conclusion}

The results from our study highly support the main assumption that an inde- 
pendent learning style plays a fundamental role in higher education. In particular, students who are more independent and less influenced by their environment are more likely to be successful in distance learning in comparison with students with a more traditional learning style. In other words, we have found empirical proof for the notion that students with independent learning style orientations are more likely to succeed in distance learning programs than those students who lack this style. Therefore, the specific design and application of distance learning is of remarkable importance to stakeholders involved in all kinds of educational institutions. Moreover, we may conclude that distance learning is not appropriate for everyone. After all, an independent learning style is practised and retained, in particular, in distance learning universities than elsewhere. All in all, our study points out that AOU students' independent learning style is a key factor to take into account when predicting student withdrawal from, or completion of, university distance education programs.

\section{Conflicts of Interest}

The authors declare no conflicts of interest regarding the publication of this paper.

\section{References}

Arab Gulf Program for United Nations Development Organizations. http://www.agfund.org

Arab League Educational, Cultural and Scientific Organization. http://www.alecso.org

Arab Open University (2018). https://www.arabou.edu.kw/bh/index.php/component/k2/item/77-agfund?Itemid=282

Astin, A. (1970). The Methodology of Research on College Impact (II). Sociology of Education, 43, 223-254. https://doi.org/10.2307/2112065

Bonk, C., \& Khoo, E. (2014). Adding Some TEC-VARIETY: 100+ Activities for Motivating and Retaining Learners. http://tec-variety.com/TEC-Variety_eBook_5-4.pdf

Bean, P., \& Metzner, S. (1985). A Conceptual Model of Non-Traditional Undergraduate Student Attrition. Review of Educational Research, 55, 485-540. https://doi.org/10.3102/00346543055004485

Boshier, B. (1973). Educational Participation and Dropout: A Theoretical Model. Adult Education, 4, 288-282. https://doi.org/10.1177/074171367302300401

Boyles, L. W. (2000). Exploration of a Retention Model for Community College Student. Doctoral Dissertation. Greensboro: University of North Caroline at Greensboro.

Braxton, M., Johnson, M., \& Shaw-Sullivan, V. (1997). Appraising Tinto's Theory of College Student Departure. In J. C. Smart (Ed.), Higher Education: A Handbook of Theory and Research. New York: Agathon Press.

Carr, S. (2000). As Distance Learning Comes of Age, the Challenge Is Keeping the Students. In Chronicle of Higher Education, Information Technology Section. https://www.chronicle.com/article/As-Distance-Education-Comes-of/14334

Diaz, P. (2002). Online Drop Rates Revisited. http://www.technologysource.org/article/online_drop_rates_revisited/ 
Diaz, P., \& Cartnal, B. (1999). Students' Learning Styles in Two Classes. Online Distance Learning and Equivalent On-campus. College Teaching, 47, 130-135. https://doi.org/10.1080/87567559909595802

Dille, B., \& Mezack, M. (1991). Identifying Predictors of High Risk among Community College Telecourse Students. The American Journal of Distance Education, 5, 24-35. https://doi.org/10.1080/08923649109526729

Frankola, K. (2001). Why Online Learners Drop Out. Workforce, 80, 53-58.

Gandhe, S. K. (1995). Role of Distance Learning in the Economic Development of South Asian Region. Distance Learning, One World Many Voices: Quality in Open and Distance Learning. In 17th World Conference of the International Council for Distance Learning (Vol. 1, pp. 265-268). Birmingham.

Garland, R. (1993). Student Perceptions of the Situational, Institutional, Dispositional, and Epistemological Barriers to Persistence. Distance Education, 14, 181-198. https://doi.org/10.1080/0158791930140203

Gibson, C. (2000). Learners and Learning: The Need for Theory. In W. G. Anderson (Ed.), A Handbook of Distance Learning. The Pennsylvania State University Press.

Hair et al. (1998). Multivariate Data Analysis with Readings. Upper Saddle River, NJ: Prentice Hall.

Kamel, S. (2002). Internet-Based Training Applicability in Egyptian Firms. Cairo: The American University Press.

Heidrich et al. (2018). Diagnosis of Learner Dropout Based on Learning Styles for Online Distance Learning. Telematics and Informatics, 35, 1593-1606. https://doi.org/10.1016/j.tele.2018.04.007

Kember, L. (1981). Some Factors Affecting Attrition and Performance in a Distance Education Course at the University of Papua and New Guinea. Distance Education, 2, 164-188. https://doi.org/10.1080/0158791810020203

Khan, M., Alam, M., \& Hossain, M. (2018). Factors Influencing on Dropouts at Undergraduate Level in Private Universities of Bangladesh: A Case Study. Australasian Journal of Business, Social Science and Information Technology, 44, 177-188.

https://www.researchgate.net/publication/324312662

Kinder et al. (2002). Student Success and Retention Task Force Report. Appendix A. https://www.ryerson.ca/lt/resources/LTO_Reports_Publications/student_success/appe $\underline{\text { ndixA.pdf }}$

Malhotra, N. K. (1999). Marketing Research: An Applied Orientation. Library of Congress Cataloguing in Publication Data.

Mashhour, A. (2007). A Distance Education Model for Jordanian Students Based on Empirical Study. Turkish Online Journal of Distance Education, 8, Article 13. $\underline{\text { http://citeseerx.ist.psu.edu/viewdoc/download?doi=10.1.1.485.205\&rep=rep1\&type }=p d}$ $\underline{f}$

McEwen, C., \& Gueldenzoph, L. E. (2003). Retaining Your Online Students. North Carolina A \& T State University Greensboro.

http://citeseerx.ist.psu.edu/viewdoc/download?doi=10.1.1.521.1615\&rep=rep1\&type=p df

Mohamed, A. (2005). Distance Higher Education in the Arab Region: The Need for Quality Assurance Frameworks. Journal of Distance Learning Administration, 8, No. 1.

Morris, L., \& Finnegan, L. (2005). Predicting Retention in Online General Education Courses. The American Journal of Distance Education, 19, 23-36.

https://doi.org/10.1207/s15389286ajde1901_3 
O’Malley, J., \& McCraw, H. (1999). Students Perceptions of Distance Learning. Online Learning and the Traditional Classroom. Online Journal of Distance Learning Administration, 2. http://www.westga.edu/\%7Edistance/omalley24.html

Nasser, R., \& Abouchedid, K. (2000). Attitudes and Concerns towards Distance Education: The Case of Lebanon. Online Journal of Distance Learning Administration. http://www.westga.edu/ distance/ojdla/winter34/nasser34.html

Parker, A. (1999). A Study of Variables Predicting dropout from Distance Learning. International Journal of Educational Technology, 1, 1-10.

https://eric.ed.gov/?q=A+Study+of+Variables+that+Predict+Dropout+from+Distance +Education.\&pr $=$ on\&id=EJ616725

Paustain, E., \& Slovenes, D. J. (2002). Reference Issue and Trends of IT Management in Contemporary Organization. Alabama: University of Alabama at Birmingham Press.

Puspitasri, K., \& Oetoyo, B. (2018). Successful Students in an Open and Distance Learning System. Turkish Online Journal of Distance Education, 19, Article 13.

Rawaf, A., \& Simmons, C. (1992). Distance Higher Education for Women in Saudi Arabia: Present and Proposed Distance Education.

Ried, D. (2010). A Distance Education Course in Statistic. American Journal of Pharmaceutical Education, 74, 1-7. https://doi.org/10.5688/aj7409172

Russell, L. (1999). The No Significant Difference Phenomenon. Raleigh, NC: State University Press.

Rwegasira, K. (1988). Administering Management Development Institutions in Africa. Avebury Gower Publishing Co.

Simpson, O. (2008). Cost-Benefit If Student Retention Policies and Practices, Economics of Distance and Online Learning: Theory, Practice, and Research.

Simpson, O. (2012). Supporting Students for Success in Online and Distance Education. Abingdon-on-Thames: Routledge.

Sweet, R. (1986). Student Dropout in Distance Education: An Application of Tinto's Model. Distance Education, 7, 201-213. https://doi.org/10.1080/0158791860070204

Thompson, M. M. (1998). Distance Learners in Higher Education. In C. Campbell Gibson (Ed.), Distance Learners in Higher Education: Institutional Responses for Quality Outcomes. Madison, WI: Atwood Publishing.

Tillman, Sr. C. A. (2002). Barriers to Student Persistence in Higher Education. https://www.whdl.org/sites/default/files/v2n1_Tillman.pdf

Tinto, V. (1975). Dropouts from Higher Education: A Theoretical Synthesis of the Recent Literature. A Review of Educational Research, 45, 89-125.

https://doi.org/10.3102/00346543045001089

Tinto, V. (1982). Limits of Theory and Practice in Student Attrition. Journal of Higher Education, 53, 687-700. https://doi.org/10.2307/1981525

Traxler, J. (2018). Distance Learning-Predictions and Possibilities. Education Sciences, 8, 35. http://www.Mdpi.com/journal/education https://doi.org/10.3390/educsci8010035

UNESCO (2002). Open and Distance Learning, Trends, Policy and Strategy Considerations. Paris: Division of Higher Education.

Willis, B. (1994). Distance Education-Strategies and Tools and Distance Education-A Practical Guide. Englewood Cliffs, NJ: Educational Technology Publications.

Yang, Y., \& Cornelius, L. F. (2005). Preparing Instructors for Quality Online Instruction. Online Journal of Distance Learning Administration. 
https://www.westga.edu/ distance/ojdla/spring81/yang81.htm

Zambalde et al. (2012). Modelling, Development and Diffusion of Hypermedia Internet Application for the Brazilian Rural Sector. International Journal of Electric Commerce Studies, 3, 165-186. 